Andrés Covarrubias C.

Profesor de la Facultad de Filosofía

Pontificia Universidad Católica de Chile

\title{
Lenguaje, belleza y verdad en Cicerón y San Agustín: las encrucijadas de la persuasión*
}

\section{INTRODUCCIÓN}

En un trabajo anterior me referí a las exigencias que impone San Agustín en el De doctrina christiana para conseguir una transformación radical de la oratoria -luego de haber despreciado durante mucho tiempo este arte por parecerle engañoso- de modo que la retórica sirva efectivamente para los fines que el orador eclesiástico pretende alcanzar (1). Ahora me propongo analizar la manera como el Obispo de Hipona supera el marco fundamentalmente relativista y legalista de la oratoria de Cicerón, para edificar un lugar en el que el lenguaje persuasivo, la belleza y la verdad confluyan en un punto central desde donde sea posible superar el relativismo radical, en cuanto este último es, en gran medida, una consecuencia de la confusión que surge respecto al problemático límite que intentamos trazar, a veces con bastante dificultad, entre la relatividad o la relación según un principio verdadero, por una parte, y un relativismo a ultranza sin referencia a un fundamento último, por otra.

Como es bien sabido, el análisis del lenguaje y sus límites constituyó una preocupación constante en el pensamiento de San Agustín. En efecto, el mayor obstáculo para el filósofo de Tagaste estriba en encontrar un lenguaje que permita referirnos de algún modo a la trascendencia, pero sin menoscabarla. Esto implica, en primer término, superar la mera palabrería propia de una retórica sin contenido, y, en segundo lugar, buscar una visión de totalidad que dé un sentido y un fundamento adecuado a los estrechos parámetros impuestos por la finitud y la temporalidad (2).

Asumiré esta investigación, en lo esencial, desde la perspectiva de la argumentación (ratiocinatio), pues desde esta última es posible aquilatar con mayor preci-

(*) Este artículo forma parte del proyecto FONDEDOC 2001 (P.U.C.Ch.), "Introducción a la retórica clásica". Fue presentado para su discusión en el VI Seminario de Estudios Patrísticos, Facultades de Teología y de Filosofía, P. Universidad Católica de Chile, en septiembre de 2001.

(1) Cfr. "La reconciliación de San Agustín con la retórica en De doctrina christiana", Diadokhé, Revista de Estudios de Filosofía Platónica y Cristiana, Santiago-Buenos Aires, vol. 1, no 1-2, 1998, pp. 83-94.

(2) Cfr. para este aspecto, A. Covarrubias: "El itinerario filosófico de San Agustín a la luz de Las Confesiones", Seminarios de Filosofía, Instituto de Filosofía, P. Universidad Católica de Chile, vol. especial, 1993, pp. 163-178. 
sión la diferencia entre las posiciones de Cicerón y San Agustín, en lo que respecta a la relación que pueda ser establecida entre lenguaje y persuasión, apariencia y verdad. La pregunta que nos guía es la siguiente: ¿en qué consiste la belleza y verdad últimas del lenguaje?

\section{LENGUAJE, ARGUMENTO Y VERDAD EN CICERÓN}

Cicerón (106-43 a. C.) comienza el libro I del De inventione afirmando que la sabiduría debe acompañar siempre a la elocuencia. Esto en vistas a la creación de una sociedad fundada en el bien común y no en la fuerza física. Un buen ejemplo de esta íntima vinculación entre sabiduría y oratoria se ha dado en los mejores hombres de entre los romanos: Catón, Lelio, Africano y los Gracos. Así, pues, se ha de estudiar oratoria para que los charlatanes no ocupen el lugar que debería estar reservado solo para los buenos ciudadanos. Se desprende de todo esto el hecho de que la retórica constituye una parte fundamental de la política, aunque asumiendo -en esto Cicerón sigue la tradición aristotélica y no la de Gorgias, para el que la retórica abarca sin límites todos los campos de la realidad- que este arte se refiere exclusivamente a los géneros deliberativo o político, epidíctico (o elogiativo y desacreditativo) y judicial.

Ahora bien, aunque Cicerón establezca tal declaración de intenciones en esta temprana obra, la que escribió cerca de los veinte años, sin embargo, y paralelamente, defenderá la tesis de que la inventio -según nuestro autor, la parte más importante de la oratoria- es el descubrimiento de los argumentos verdaderos o aparentemente verdaderos que convierten un caso argumentativo en un caso probable. Esta apariencia de la verdad o verosimilitud, en efecto, es aceptada debido al carácter eminentemente judicial de la retórica ciceroniana (3). Esto, entre otras cosas, implica la utilización de ciertas estrategias como la simulación y la ocultación (4), que distan de estar entre los objetivos de la oratoria, desde el punto de vista asumido por San Agustín.

Lo que apoya, según Cicerón, al argumento retórico y sus proposiciones, son los atributos de personas o de acciones. Pero generalmente nos movemos dentro de

(3) Agradezco las observaciones del Profesor Francisco Fortuny, de la Universidad de Barcelona, en lo que respecta a las dificultades de entender la ética ciceroniana como una ética eminentemente jurídica y, por ende, relativista. Sin embargo, me parece consistente la argumentación de Manfred Fuhrmann en "Cicerón y la retórica: la moral de abogado de Cicerón y su evaluación en los siglos XIX y XX", Anuario Filosófico, U. de Navarra, vol. XXXIV/2, 2001, pp. 347-367, donde analiza la influencia determinante que tuvo en Cicerón la solución aristotélica de una retórica moralmente neutra de la probabilidad, opuesta a las posiciones relativistas de algunos sofistas y a las estrictas exigencias platónicas. De aquí que el abogado y orador Cicerón, llevara en ocasiones al extremo las tergiversaciones de los hechos y el engaño para defender su causa, asumiendo como límite solo la plausibilidad, sin un compromiso ético (cfr. p.e. los informes Pro Cluentio Habito y Pro Milone). En este sentido, Cicerón, desde una perspectiva eminentemente judicial, "se consideró en el derecho de conceder parcialidad a las partes y sus defensores, con la condición de que los jueces no cediesen ni lo más mínimo en lo que consideraban verdadero" (p. 366). Ahora bien, la jurisprudencia actual, a pesar de asumir en lo esencial la ética de abogado ciceroniana, se ve limitada por la obligación a la verdad y la prohibición del encubrimiento punible (cfr. p. 367) 
lo probable y no de lo necesario, donde la probabilidad es aquello que ocurre usualmente o que se encuentra en las creencias comunes de las personas, o también, es lo que encierra en sí mismo una semejanza con tales cualidades (cfr. De inv. I, 45). Mas aún, toda argumentación debe ser realizada por analogía o por entimema. La primera, parte de hechos aceptados hacia la aprobación -precisamente en virtud del principio analógico- de una proposición dudosa. El entimema, en cambio, es una forma argumentativa que extrae una conclusión probable a partir de los hechos considerados. Todavía más, la expresión 'argumento' significa en Cicerón una afirmación sobre cualquier asunto probable o cierto, pero también puede significar el adorno o embellecimiento de una afirmación acerca de algo (De inv. I, 65 ss.). Es así como en Topica 8, Cicerón define el 'tópico' como el lugar en el que residen los argumentos $\mathrm{y}$, además, define un argumento como todo aquello que convierte en creíble un asunto dudoso (5).

Por último, la peroratio o conclusión está íntimamente asociada con el hacer surgir sentimientos en el auditorio: animadversión respecto al rival, aceptación afectiva de nuestro discurso. Una vez alcanzada la emoción que queremos de parte del jurado, no debemos alargarnos en el discurso, sino calcular bien, porque, como dice Cicerón, nada hay que se seque más rápido que las lágrimas.

Por otra parte, la oratoria debe utilizar al máximo la conjetura y, en este sentido, la investigación de los hábitos, emociones, intereses, propósitos, logros, acciones pasadas y discursos, constituyen un excelente material para producir 'sospechas conjeturales' ( $D e$ inv. II, 30). Incluso los rumores, tanto para el que acusa como para el que defiende, constituyen elementos importantes para producir la amplificación oratoria. Esta postura de Cicerón rebasa el debate judicial, para proponer un estilo semejante de argumentación, que influye en la retórica deliberativa o política, la que versa sobre lo honorable, entendido esto último como algo compuesto por sabiduría, justicia, valor y moderación. Sin embargo, estas 'virtudes' continúan dependiendo de la estrategia persuasiva dispuesta y acomodada por el discurso y, por lo tanto, siempre quedan sujetas a los dictámenes de la conveniencia, la que, en fin, depende de cada caso a resolver.

En el diálogo De oratore, Cicerón matiza y pule las ideas que un tanto toscamente había barruntado en el De inventione, sobre todo las que hacen relación con las emociones y el lugar que ocupan en el proceso de persuasión. Es importante destacar aquí que Cicerón recurre a Craso como "portador de sus propios puntos de vista sobre la materia (oratoria), a saber, que la retórica es un modo de vida en sí misma y que el orador es una mezcla cultural de filósofo, abogado y político" (6). En opinión de Craso, el perfecto orador mantiene su dignidad, pero también debe preservar la del Estado (De or. I, 34) (7). Escévola, renuente a asignar un papel tan

(5) Itaque licet definire locum esse argumenti sedem, argumentum autem rationem, quae rei dubiae faciat fidem.

(6) Cfr. Donovan J. Ochs, “Teoría retórica de Cicerón”, en Sinopsis histórica de la retórica clásica, Ed. James J. Murphy, Gredos, Madrid, 1989, p. 156. En De oratore III, 130 s., Craso afirma que no le preocupa que usemos la etiqueta de filósofo o de orador, con tal de que el personaje en cuestión presente un asunto importante de una manera elocuente.

(7) Sic enim statuo, perfecti oratoris moderatione et sapientia non solum ipsius dignitatem, sed et privatorum plurimorum et universae rei publicae salutem maxime contineri. 
importante a la elocuencia, sostiene que fueron los consejos sabios y no el arte oratoria quienes crearon el orden de las comunidades, y se pregunta: ¿no son la religión y la ley más importantes? (ibid. I, 40). Más aún, Escévola afirma que la pretendida superioridad dialéctica de la oratoria no es más que un engaño (ibid.). Sin embargo, lo que nos interesa ahora es la respuesta de Craso: la objeción de Escévola es la de los filósofos griegos, como Platón, y agrega que está en desacuerdo con ellos como está en desacuerdo con Platón, por ser el impulsor de tal idea ( $D e$ or. I, 49) (8). Incluso, según Craso, para suscitar ciertas emociones, el orador tiene que ser un conocedor de la filosofía natural, cosa que supera con creces la mera charlatanería. Se necesita, pues, de un profundo conocimiento de la naturaleza humana, lo que es terreno propio de la filosofía. Tanto Escévola como Antonio, que es abogado, acusan a Craso de proponer un ideal inalcanzable, ni siquiera remotamente rozado por el mismo Craso.

Sobre todo, en Craso hay un fuerte intento por aproximar al filósofo y al abogado. En efecto, dice que tanto uno como el otro se ocupan de las obligaciones, las recompensas, las sanciones, el control de las emociones, la propiedad, etc. Antonio, en cambio, separa ambas figuras y la del político respecto de la del orador, definiendo a este último como aquel que usa un lenguaje agradable y argumentos convincentes en las situaciones judiciales y deliberativas. También querría -agrega Antonio- que fuese instruido en el empleo de la voz y de la actuación, y que tuviese un cierto encanto personal (De or. I, 213). Recomienda, además, recurrir a los especialistas para resolver los asuntos complejos. El orador es, para Antonio, en fin, un hombre que puede hablar de modo tal que logre persuadir a los oyentes (ibid. I, 260).

En el libro II del De oratore, Antonio expone, y ya no en vistas a la refutación de Craso, su punto de vista, y circunscribe la oratoria al género epidíctico, pues para ensalzar o vituperar a alguien no se requiere de grandes conocimientos. La oratoria, según Antonio, tiene el defecto de no poder cambiar la mente de los individuos. Es así como él exige para el orador, sobre todo, la capacidad de imitar modelos excelentes, también en el ámbito de lo moral (De or. II, 90 ss.). Dice Antonio que los romanos rara vez han confiado en los filósofos, y si un orador muestra sus conocimientos filosóficos, su credibilidad e influencia quedan disminuidas (ibid. II, 156 s.). Aconseja, asimismo, vincular estrechamente una prueba a una emoción, ya que la mayoría de las decisiones se fundamentan en una emoción. Desde el punto de vista de Antonio, pues, la clave de la persuasión está cifrada en el uso adecuado de las apariencias y en la capacidad para mover al auditorio (ibid. II, 337).

Cicerón en Brutus (46 a.C.) defiende la idea de que es el auditorio, en definitiva, el que aporta la prueba última de la valía de un orador, de su éxito (ibid. 184), aunque la gente común se conmueva al escuchar a un orador sin saber por qué se conmueve. El crítico, que es versado en el arte retórico, por el contrario, sabe por qué es influenciado el oyente, y conoce las cinco partes de este arte: invención, disposición, pronunciación, estilo y actuación.

(8) Este es, a mi entender, el planteamiento de Platón en el Gorgias, donde el filósofo propone una descalificación radical de la retórica, más que el punto de vista del Fedro, diálogo en el que defiende una oratoria filosófica al servicio de la verdad. 
Este punto es, a mi juicio, uno de los más relevantes cuando comparamos las posiciones de Cicerón y San Agustín respecto de la oratoria. En efecto, para el Obispo de Hipona el auditorio no es determinante, y las partes fundamentales de la oratoria son la invención y la exposición, separándose del aparato teatral que Cicerón consideraba necesario, vistas las cosas desde una perspectiva judicial. Además, a pesar de que para Cicerón la elocuencia ha hecho más por la civilización que la milicia, según él, sin embargo, no debe aquilatarse la oratoria por su utilidad. San Agustín, por el contrario, se detiene precisamente en su calidad de medio útil, frente a lo que debe ser valorado por sí mismo, que es únicamente el mensaje de las Escrituras (9). Las fuentes de Cicerón, obviamente, se agotan con el estudio de la oratoria y de la dialéctica (10), aspectos que constituyen solo un simple instrumento para el filósofo de Tagaste.

\section{LENGUAJE, RETÓRICA Y VERDAD: LA SUPERACIÓN DE LA AMPU- LOSIDAD Y LA APARIENCIA EN FAVOR DE LA SENCILLEZ DE LA VERDAD -ORATOR VS. DE DOCTRINA CHRISTIANA (11)-}

Cicerón publica el Orator bajo la forma narrativa de una carta a Bruto, exponiéndole las características del perfecto orador. San Agustín, en el libro IV del De doctrina christiana, hace algo semejante, pero atendiendo a características diferentes de las aducidas por Cicerón. Desarrollaré la posición de este último, comparándola con la de San Agustín, en los tres planos que enmarcan los officia oratoris, a saber: enseñar (docere), deleitar (delectare) y, en fin, mover o modificar el ánimo de los oyentes (flectere).

\section{El docere agustiniano, más allá de la prueba persuasiva en Cicerón}

Con respecto a la enseñanza que debe recibir el orador, Cicerón sostiene que la filosofía constituye un componente esencial en lo que hace relación con la educación que debe ser impartida al rétor ideal, en vistas a perfeccionar la capacidad de exponer con mayor calidad sus argumentos. Así lo demuestran las trayectorias de Pericles y Demóstenes. A la inversa, también la retórica es necesaria para adornar las materias tomadas de la filosofía. La juntura de ambas disciplinas permite, en

(9) Philip E. Satterthwaite en "The Latin Church Fathers", Handbook of Classical Rhetoric in the Hellenistic Period, Ed. S. E. Porter, Leiden, Brill, 1997, cap. 22, p. 676, afirma: "The work most cited by the Latin Fathers is the Bible, of which they all show an extensive knowledge. Biblical exegesis, in an innovation of classical rhetorical procedure, is now an acceptable form of argument".

(10) Dice Cicerón que en Atenas estudió filosofía con Antíoco y retórica bajo la enseñanza de Demetrio. Sus compañeros de viaje eran los más excelentes oradores del Asia Menor, pero luego fue a Rodas para estudiar con Molón. Este se encargó de reprimir sus excesos, de tal manera que, al volver a Roma, se percibía a sí mismo un orador diferente (Brutus, 315 ss.).

(11) Los tres primeros libros de esta obra, que tratan sobre el modus inveniendi, fueron escritos a partir del año 397 d. C., dejando inconcluso el III hasta 15, 35. A cinco años de su muerte, en el 426, Agustín terminó el De doct. christ. III y redactó por completo el libro IV, sobre el modus proferendi (cfr. Retract. II, 31, 1). 
efecto, la existencia de oradores realmente elocuentes (Orator, 15). El verdadero orador debe estar familiarizado, por lo dicho más arriba, con los tópoi de la argumentación y los lugares del razonamiento (ibid. 44) (12), los que en el Orator, 113, circunscribe a la ciencia de la dialéctica (13), tal como fueron enseñados por Aristóteles y Crisipo. En Partitiones oratoriae (46 a. C.), Cicerón insiste en el hecho de que, dentro del campo de la invención, y puesto que el orador tiene como fin persuadir al auditorio, el rétor debería extraer sus argumentos de los tópoi y, una vez encontrados, organizar adecuadamente los argumentos (cfr. 5-10). Pero no solo deberá entender de dialéctica, sino que también sabrá tratar los conceptos filosóficos de religión, deber, placer, etc., ya que el orador elocuente encuentra situaciones donde desarrollar estos temas (De or. 118 ss.). Además, debe conocer muy perfectamente el derecho civil y la historia. Pero, en definitiva, y a pesar de los contenidos, el ornato es lo que enmarca la esencia de la oratoria, aspecto que, por lo demás, es arduamente criticado por San Agustín.

En fin, en los Topica (44 a. C.) Cicerón sostiene la conveniencia de fusionar, bajo una metodología común, la invención filosófica (tal como la desarrollara Aristóteles) y la invención retórica (14).

San Agustín intenta ir más allá de Cicerón, al enseñar una doctrina no verosímil sino verdadera. Pero, sin duda, y a pesar de no contravenir el sueño de San Jerónimo, el que le advierte a este último "Ciceronianus es, non Christianus" (Ep. $22,30,4)$, asume muchos de los aspectos capitales de la concepción oratoria de Cicerón, pero modificando sustancialmente la procedencia y la certeza de los tópoi desde los cuales se ha de investigar. Ya no se trata de convicciones populares recogidas de aquí y allá, sino de la doctrina de las Sagradas Escrituras, con lo cual la oratoria asume una perspectiva hermenéutica nunca antes desarrollada en la historia.

\section{Delectare: la belleza del lenguaje}

Según Cicerón existen dos clases de oradores, "los que hablan en términos sencillos e instructivos y aquellos otros que usan la exuberancia, la locuacidad y las cadencias rítmicas para mover a sus oyentes. Cicerón se inclina por estos últimos" (15). Aquí, es decir, en el ámbito del estilo, ya encontramos una diferencia esencial con respecto a San Agustín: este prefiere a todas luces el estilo sencillo, aunque con pinceladas del medio y del sublime, para la predicación de las Escrituras.

Esto se vincula al hecho de que el objeto a tratar no es la persuasión de un auditorio, sino la mejor entrega que se pueda ofrecer de la verdadera doctrina cristiana, objetivo primordial del orador eclesiástico. Cicerón, en cambio, dice que el perfecto orador ha de usar el estilo sencillo para probar su caso, el medio o templa-

(12) Noverit igitur hic quidem orator, quem summum esse volumus, argumentorum et rationum locos.

(13) También debería conocer, dice Cicerón, la naturaleza de las palabras tanto aisladas como en construcción, los métodos para determinar la verdad o la falsedad de las cosas, las maneras de resolver la ambigüedad, el modo de definir lo que una cosa es y las relaciones que hay entre especie y género (Orator 115).

(14) Cfr. J. J. Murphy (ed.): op. cit., p. 206.

(15) Ibid. p. 193. 
do para encantar a los oyentes, y, en fin, el sublime o elevado para doblegar al auditorio (De or. 70 ss.). Los dos primeros estilos mencionados tienen la función de preparar a los oyentes, asumiendo el último, es decir el sublime, la mayor importancia (ibid. 85).

San Agustín, como hemos dicho, defiende el estilo sencillo por la simple razón de que es el que más se acomoda a las Escrituras, las que son modelo, a la vez, de sabiduría y recta elocuencia. De modo que aunque las cosas se entiendan, deleiten y muevan menos, sin embargo, se ha de preferir decir siempre las verdaderas y justas (cfr. De doct. christ. IV, 14, 30). ¿Qué significa esto en la práctica? Que la auténtica vocación de la oratoria es la verdad y que solo en esta reside la belleza. Cicerón, en cambio, y puesto en la encrucijada entre verdad y conveniencia, sacrifica a la primera en pos del lenguaje persuasivo y, exclusivamente en este último, hace habitar la belleza.

\section{Flectere: la influencia en los oyentes}

Pensando en los auditores, Cicerón coloca, en el caso de la presentación retórica, a la actuación (i.e. tono de voz, gesto, semblante) y la elocución (i.e. uso del lenguaje) en un nivel equivalente, pues la elocuencia es imposible sin un total dominio de la actuación (De or. 55) (16), cuando se busca despertar o apaciguar las emociones del auditorio (17). Ahora bien, para Cicerón la mayor importancia en lo que hace relación con los oyentes es el estilo, sea rítmico o periódico. ¿Por qué? Porque lo que guía esta parte de la oratoria es la utilidad y, desde este punto de vista, pensamiento y dicción deben organizarse por parte del orador de un modo flexible, para suscitar un adecuado placer en el oyente.

En el caso del discurso deliberativo, Cicerón separa las estrategias del orador, dependiendo del grado de preparación del auditorio: cuando uno se dirige a una audiencia poco instruida y carente de formación cultural, lo mejor es alegar utilidad; cuando uno se dirige a una audiencia culta, lo mejor es aducir verdadero mérito. Esto se basa en que los seres humanos están, en general, más inclinados a evitar el mal que a hacer el bien (cfr. Part. orat. 85 ss.) (18).

Para San Agustín, no basta con conmover el ánimo de los oyentes. Vencer significa que tal ánimo cambie en virtud de las cosas buenas y justas (De doct. christ. IV, 13, 29). Así, pues, y situándose en el polo opuesto con respecto a Cicerón, el Obispo de Hipona entiende que el orator debe hablar solo cosas justas, santas y buenas, además de tratar materias grandes, aunque no consiga el asentimiento de los auditores (ibid. IV, 17, 34). Esto último, es decir, la indiferencia o el rechazo de los oyentes, es totalmente inaceptable desde el punto de vista de la oratoria propugnada por Cicerón, puesto que para este autor vencer significa convencer, sin concesiones.

(16) Est enim actio quasi corporis quaedam eloquentia, cum constet e voce atque motu.

(17) El carácter del hombre, dice Cicerón, logra frecuentemente el favor del jurado, pero favorece mucho más a la oratoria todo aquello que fomenta el despertar de las emociones (cfr. De or. $120 \mathrm{~s}$.).

(18) (...) hominum esse duo genera, alterum indoctum et agreste, quod anteferat semper utilitatem honestati, alterum humanum et politum, quod rebus omnibus dignitatem anteponat. 


\section{CONCLUSIÓN}

Forbes I. Hill ha escrito, al finalizar un estudio sobre la retórica de Aristóleles, lo siguiente: "Cicerón y Quintiliano son moralistas los dos, pero ni ellos ni sus seguidores desarrollaron un sistema de valores como soporte de los argumentos (retóricos) que recomiendan. Por ello, al sostener la idea de neutralidad moral de la retórica, resultan, de hecho, más consecuentes que Aristóteles" (19). Dejando de lado la problemática comparación establecida aquí con la teoría retórica de Aristóteles, en lo que concierne al compromiso moral, es posible plantear que San Agustín, en el De doctrina christiana, ha seguido una vía radicalmente distinta de la neutralidad moral de Cicerón en lo que respecta a la oratoria, lo que distancia al Obispo de Hipona de las posiciones de este último.

Esta diferencia se extiende también al papel que la religión ha de ocupar en este contexto: mientras que para Cicerón la religión constituye un aspecto relacionado con ciertas opiniones comunes que el orador debe manejar para lograr una mejor persuasión, en San Agustín, en cambio, la religión, expresada en las Sagradas Escrituras, fundamenta objetivamente la verdad de aquello que se ha de argumentar, y a este objetivo capital sirve el arte de la retórica. A mi juicio, A. Mandouze ha calificado acertadamente el De doctrina christiana de San Agustín como el De oratore cristiano, precisamente haciendo referencia a la obra de Cicerón como fuente inspiradora, pero atendiendo a la vez a la aportación novedosa de San Agustín, que la trasciende desde el punto de vista del compromiso moral exigido al orador (20).

Así, pues, lenguaje, belleza y verdad constituyen una unidad indisoluble y fontal para San Agustín. En Cicerón, por el contrario, esta vinculación es débil, al optar por la mera verosimilitud y orientar la oratoria, casi por completo, a la persuasión del auditorio bajo un modelo de corte judicial. En San Agustín la verdad, y más aún, la verdad revelada, aquella en la que reside la auténtica sabiduría, da sentido y límites a la retórica -que es de suyo neutral para defender la verdad o abusar de los oyentes mediante la falsedad (in medio posita, dice San Agustín en De doct. christ. IV, 2, 3)-, adquiriendo así, en el Obispo de Hipona, un lugar secundario la persuasión efectiva del auditorio a toda costa, pues el modelo retórico, en este caso, está delineado por el paradigma bíblico de la convicción absoluta acerca de donde reside la verdad. En Cicerón, la mera verosimilitud es tanto punto de partida como punto de llegada, porque la oratoria se define por el auditorio y lo que a este último le parece verosímil, siguiendo el curso muchas veces sinuoso de sus inestables creencias.

A partir de los aspectos mencionados, es posible diferenciar entre enseñar con certeza o solo probar de un modo verosímil. La enseñanza cierta, en efecto, se hace cargo de la relatividad, iluminándola y acogiéndola mediante la luz inamovible de la verdad. La prueba meramente verosímil, que siempre presenta una diversidad de grados en aquellas cosas humanas sujetas a la opinión y la creencia, termina por conducir, llevada al extremo, al relativismo con respecto a la verdad,

(19) Cfr. J. J. Murphy (ed.): op. cit., p. 111.

(20) Cfr. "Saint Augustin ou le rhéteur canonisé", Bulletin de l'Association G. Budé, serie 4, n 2 , 1955, pp. 37-41. 
toda vez que no puede encontrar un sólido soporte en la verdad trascendente, que irrumpe como fundamento incuestionable cuando es considerada desde la óptica de la revelación (21).

En fin, la distancia que va de la relatividad al relativismo radical, es la que va desde una serie o gradación sin un término último al cual referirse, y que sirve como medida de la serie, por una parte, y una serie aparentemente plausible que no ofrece un criterio estable para la gradación de la misma, por otra. En la relatividad se muestra la auténtica condición humana. En el relativismo, en cambio, se filtra el sofisma -que afecta todo el horizonte vital, como lo experimentó el mismo Agustín antes de su conversión- de intentar fundamentar un orden prescindiendo de un auténtico y sólido principio regulador, el que es exigido, sin embargo, por este mismo orden que se pretende establecer.

\title{
RESUMEN
}

En este artículo me propongo mostrar las profundas diferencias entre Cicerón y San Agustín, desde el punto de vista de sus respectivas visiones del arte retórico. Mientras que, para el primero, la oratoria se ampara en el horizonte de las meras probabilidades, teniendo como fin la persuasión del auditorio, para el Obispo de Hipona, en cambio, el referente último está marcado por el hallazgo de la verdad, a partir de las Sagradas Escrituras. En efecto, Cicerón construye una teoría retórica compatible con la argumentación que debe dominar un buen abogado, sin las limitaciones de la obligación a la verdad y la prohibición del encubrimiento punible, mientras que San Agustín, en el De doctrina christiana, busca el establecimiento de una retórica consecuente con las aspiraciones de un auténtico orador eclesiástico. Debido a la diferencia de objetivos propuestos por cada uno de estos filósofos, mientras Cicerón se aproxima cada vez más a una posición relativista, San Agustín, aceptando la relatividad, busca, sin embargo, una práctica oratoria compatible con la expresión más pura y fidedigna de la verdad.

\begin{abstract}
In this article, I attempt to show the profound differences between Cicero and Saint Augustine concerning the rhetorical art. According to Cicero the oratory makes sense in the context of mere probabilities and aims at convincing the audience. Saint Augustine, on the contrary, thinks the scope of the oratory is given by finding truth in the Holy Scriptures. Indeed, Cicero states his theory as compatible with the arguments which a good lawyer should have, no matter they do not follow truth or hide what is against law. In De doctrina christiana, Saint Augustine prefers to state a rhetoric coherent to the aspirations of the authentic ecclesiastical orator. So, it is due to their different theories that Cicero approaches to a relativism, but Saint Augustine, though he accepts relativity, seeks an oratory practice compatible to the purest expression of truth.
\end{abstract}

(21) Cfr. P. E. Satterthwaite, cap. cit., p. 692: “... Augustine seems to differ from classical rhetorical treatises in two aspects: his downplaying of eloquence (in particular, rhetorical rules) in favour of truth; and his esteem for the Bible (and Christian writings) as literary models". 